\title{
Research on Residential Quarters Based on the Concept of Sponge City
}

\author{
Hu Jiayu, Li Manhua, Shu Yang* \\ Urban Design Institute, Wuhan University, Wuhan, China

\section{Email address:} \\ 178120029@qq.com (Hu Jiayu),1286193849@qq.com (Li Manhua),1318579332@qq.com (Shu Yang) \\ *Corresponding author
}

\section{To cite this article:}

Hu Jiayu, Li Manhua, Shu Yang. Research on Residential Quarters Based on the Concept of Sponge City. Science Discovery. Vol. 7, No. 6, 2019, pp. 385-389. doi: 10.11648/j.sd.20190706.12

Received: November 2, 2019; Accepted: December 4, 2019; Published: December 9, 2019

\begin{abstract}
In order to solve the increasingly serious water environment problem in China, the concept of Sponge City is gradually being applied to urban construction. As one of the carriers of the sponge city, the Sponge Community area has an important impact on the urban stormwater management work and plays a key role in urban construction. Compared with the traditional community, the Sponge Community can effectively collect and allocate rainwater, establish an effective relationship between the hard building landscape and the natural environment, and effectively improve the ecological climate and ecological environment of the community. In this paper, through the combination of literature collection research, empirical analysis and theoretical analysis, based on the existing research in China, combined with the relevant theories of Sponge City, comprehensive analysis of the constituent elements of Sponge City, such as vertical greening and rain garden, The specific measures most suitable for the Sponge Community are summarized as follows: concave green space, permeable pavement and other technical measures. At the same time, through the combination of practice and theory, the unique Sponge City Water circulation mechanism is summarized. Finally, through the analysis of the current situation of the Sponge Community and the current development of the sv, the problems and solutions encountered in the middle and late stages of the Sponge Community design are expounded, in order to draw some inspirations for the development of the Sponge Community.
\end{abstract}

Keywords: Water Environment, Sponge City, Sponge Community, Residential Water Cycle

\section{基于海绵城市理念下的住宅小区研究}

\section{胡嘉渝, 李满花, 舒阳"}

武汉大学城市设计学院, 武汉, 中国

\section{邮箱}

178120029@qq.com（胡嘉渝），1286193849@qq.com（李满花），1318579332@qq.com（舒阳）

摘要: 为了解决我国日趋严重的水环境问题, 海绵城市理念正逐步运用到城市建设中去。而海绵住区作为海绵城市的 载体之一, 对于整个城市雨洪管理工作有重要影响, 在城市建设中发挥着关键作用。相较于传统社区, 海绵社区能够 有效地蓄集、调配雨水，在硬质建筑景观和自然环境之间建立起有效联系，有力改善小区生态气候和生态环境。本文 将通过文献收集研究、实证分析与理论分析相结合的方法, 在我国现有研究的基础上, 结合海绵城市其相关理论, 对 海绵城市构成要素如垂直绿化、雨水花园等进行综合分析, 从而总结出最适合海绵社区的具体措施如下凹式绿地, 透 水铺装等技术措施, 同时也通过实践和理论相结合方法分析总结出独特的海绵城市水循环机制等。最后通过海绵社区 现状分析和目前海绵社区发展阐述海绵社区设计前中后期所遇到问题及解决办法，以期得出某些对海绵社区发展有益 的启示。 
关键词: 水环境, 海绵城市, 海绵社区, 住区水循环

\section{1. 海绵城市相关概念介绍}

\section{1. 海绵城市概念介绍}

海绵城市是新一代雨洪管理概念, 是指城市在适应环 境变化和应对雨水带来的自然灾害等方面具有良好的弹 性，也可成为“水弹性设计”。即下雨时吸水、蓄水、渗水、 净水, 需要时将蓄存的水“释放”并加以利用 $[1]$ 。

\section{2. 海绵城市发展现状}

我国在早期的城市建设中，强调适应性，强调绿色生 态理念, 强调可持续发展观, 就与海绵城市的理念不谋而 合。在2012年之前, 我国已有类似于海绵城市的生态弹性 城市理念出现， 2012年4月在《2012低碳城市与区域发展 科技论坛》中，海绵城市的概念首次提出。2015年4月确 定第一批海绵城市试点, 2016年4月确定第二批海绵城市 试点。2016在全国住房和城乡建设工作会议上, 提出 加快推动海绵城市建设。2017年要抓好120个试点项 目, 现已有 30 个试点海绵城市开展 [2]。

现在海绵城市试点项目已经落地开花, 项目推进速度 超出预期。第一批16个试点城市已经全部公布了海绵城市 建设项目实施规划, 三年实施计划试点区域总面积为 435 平方公里。就目前国内海绵城市发展现状看来, 有约 200 个城市已然初步拟定了“海绵城市”的相关设计方案 [3]。海 绵城市建设已遍地开发, 初见成效, 在解决城市内涝、促 进产业发展方面均取得效果。

\section{2. 海绵社区相关概念介绍}

\section{1. 海绵社区概念介绍}

“海绵社区”, 顾名思义, 就是指社区能够像海绵一样, 在适应环境变化和应对自然灾害等方面具有良好的“弹性”。 “海绵型社区”相较于传统住区, 能够有效地蓄集、调配雨 水, 在硬质建筑景观和自然环境之间建立起有效联系[4]。

海绵社区即对住区进行海绵城市设计, 在住区设计开 始之前通过城市设计的一系列方法先考虑住区水循环布 局, 再进行建筑布局和立面形式的设计。如果将海绵城市 看作集合, 那么社区设计就是其中的一个子项, 类似于有 机体对细胞, 房屋对砖块的关系。海绵城市与住区相辅相 成, 住区作为载体, 海绵城市设计作为设计方法, 两者合 二为一, 成为海绵住区。海绵社区可分为三个部分: 雨水 收集, 雨水净化处理和雨水的回收利用。

\section{2. 海绵社区发展现状}

2014年《海绵城市建设技术指南》的发布, 以及 2015 年首批国家级“海绵城市”建设试点城市名单的确定, “海 绵城市” 跃升为了近期城市建设和园林景观行业的热点词 汇[5]。
仇保兴在《海绵城市（LID）的内涵、途径与展望》 一文中, 将海绵城市建设系统从大到小划分成四个子系统, 即区域, 城市、社区、建筑, 四个层次。强调海绵社区建 设作为海绵城市建设中的重要一环, 起着承上启下的关键 性作用[6]。随着各地陆续加入海绵城市的试点名单中, 各 地建设海绵城市的详细实施方案陆续出台, 其中更是细化 了对于“海绵社区”的建设要求。江苏省住建厅在其《关于 推进海绵城市建设的指导意见》中指出, “新建住宅小区 应提前规划建设雨水系统, 室外步行道、停车场应采取透 水铺装, 政府投资的保障房等项目要率先落实。在城市低 洼易淹易涝的老旧小区改造过程中，同时考虑海绵城市建 设技术与排水设施能力建设两项措施。”济南更是将建筑 小区系统的居民小区“海绵系统”的建设作为其海绵城市 建设的五大系统之一, 成为今后居住小区建设和改造的重 点内容。2015年园冶杯住宅景观奖也在征集传统住宅景观 项目的基础上, 增加了对于优秀“海绵社区”项目的征集, 并增设了“优秀宜居住区、海绵社区开发商”奖项，以鼓励 地产商开发建设更多优质的宜居、海绵社区项目 [7]。

\section{3. 海绵住区设计的具体策略}

海绵住区设计笔者经过调查研究总结出三点, 其中两 点关于技术层面, 一点关于居民意识方面, 技术层面是关 于海绵住区水循环系统的解释以及海绵住区具体设施研 究, 意识方面是关于如何提高居民们自发的节水和爱水意 识。从实际案例和调查研究中我们可得出海绵城市的具体 攻克措施的最大关键点是不透水面如何转化为透水面, 我 们所采用的雨水花园, 下层式绿地以及植草沟, 透水铺砖 等具体绿色基础设施, 都是为了解决此问题。

\section{1. 透水面的增加}

从城镇化进程来说, 我们调查到城市内涝问题最重要 的原因是城市居住用地面积不断增加, 耕地、林地、草地 为主的渗水下垫面被居住区不透水硬化地面替代。不透水 面的增加直接破坏了自然水文循环, 影响了雨水下渗、净 化、收集等。但城镇化进程是不可避免的。所以需采取相 关解决策略, 转化尽可能多的不透水面为透水面以创造出 绿色水循环可持续小区。

海绵社区可分为新建小区的海绵设计和老旧小区的 海绵改造。这里我们主要分析的是新建小区的海绵改造。 新建小区可从这三个方面考虑透水面的增加, 一是建筑布 局可考虑集中式布局, 留出中心大花园做下沉式绿地或雨 水花园设计。二是广场、停车场、人行步道等可尽量考虑 透水铺装。三是建筑立面可采取垂直绿化, 垂直绿化植物 的选用以及立面装饰材料透水性的选用都可以增加透水 面。四是屋顶花园的设计, 可软化硬质屋顶, 提供雨水缓 存储蓄容器。 


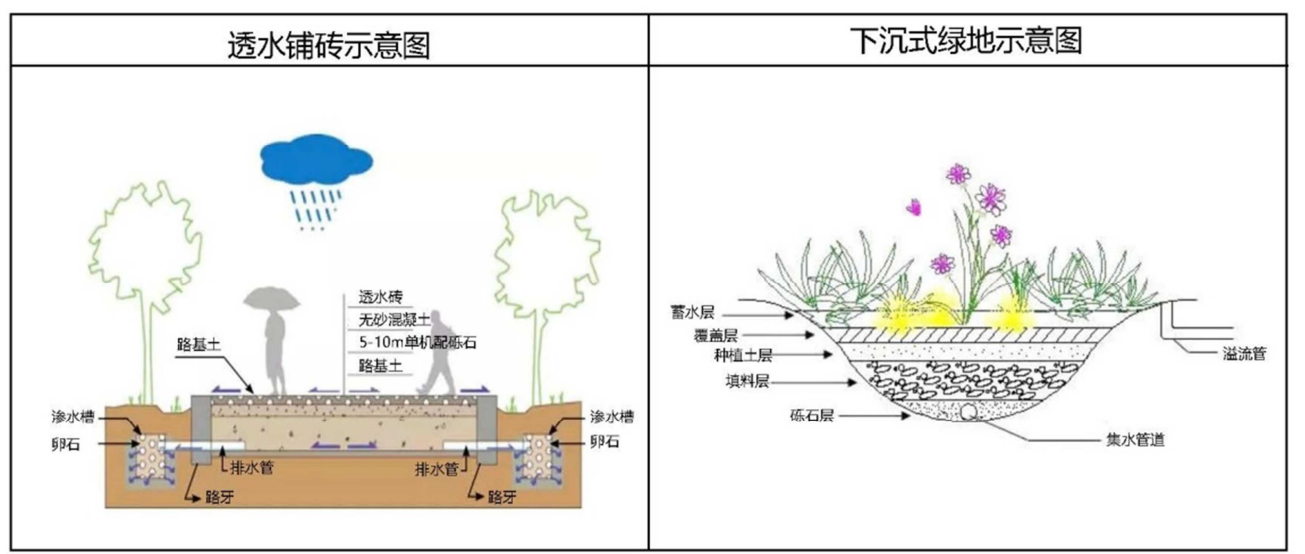

图1 海绵设施示意图（图片来源：作者整理）。

\subsection{1. 下沉式绿地设计与雨水花园设计}

下凹绿地指高程低于周围的路面, 或者铺砌硬化地面 约 $20 \mathrm{~cm}$ 的绿地。在降雨时, 下凹绿地可让雨水较大程度地 渗入绿地中, 增加土壤中的水资源, 减少绿地浇灌量。下 凹绿地还可通过土壤渗透、植物过滤等一系列作用, 有效 削减渗入雨水中的污染物 [8]。同时, 灰色设施的减少、绿 色设计的增多, 创造了良好的生态环境, 给人们带来舒适 与美的感受。雨水花园与下沉式绿地的区别在于雨水花园 是面积稍大的种植洼地, 景观元素的可选性更多更灵活, 可作为大的景观节点, 成为一个很好的休㮩空间。但下沉 的深度更深, 景观的人工化设计程度更明显, 在使用功能 上往往结合了硬质铺地广场的部分功能, 具有汇集人流, 作为活动空间的作用。一般整体设计时，下沉式绿地会与 雨水花园, 景观小品结合设计, 给居民营造良好的景观感 受。

\subsection{2. 透水铺装的采用}

透水铺装指将孔隙率较高、透水性较好的材料应用于 道路路面, 以便于渗透、存蓄、排出雨水, 削减径流[9]。 值得一提的是因为道路根据用途不同, 承载力也不同, 所
以也会采用透水铺装和不透水材料相结合的做法。一般的 透水性路面指的是透水沥青混凝土铺装, 如普通机动车 道, 会在表面采用透水沥青混凝土铺装, 为避免雨水浸入 路基, 影响道路强度, 在路面结构的基层和中下面层采用 非透水性材料等, 如高层住宅小区的住宅中心广场, 需要 承受高密度人群的踩踏活动, 可采用不透水石料与彩色透 水混凝土、透水路面砖等透水材料组合铺装的形式, 既满 足承载要求, 也满足水渗透要求 [10]。

\subsection{3. 建筑立面的垂直绿化}

海绵住区的垂直绿化设计可分几种，如图2所示，一 是传统的植物攀援式的方法, 可选取爬山虎等植物, 外墙 材料可选择大孔混凝土。二是通过建筑处理手法进行退台, 掏洞等处理, 与活动空间相结合, 形成半开敞式活动空间 $[8]$ 。与墙壁相连的平台或地面设置雨水蓄水箱, 收集过滤 雨水。活动空间可用绿化植物覆盖且进行景观设计, 与居 民娱乐观景活动相结合。三是通过建筑材料和建筑结构形 式的转变。如外墙材料采用模块式栽植盆, 顺着墙壁设置 集水槽, 在建筑底部设置积水箱, 达到收集雨水, 渗透雨 水，积蓄雨水以及再回收的目的。

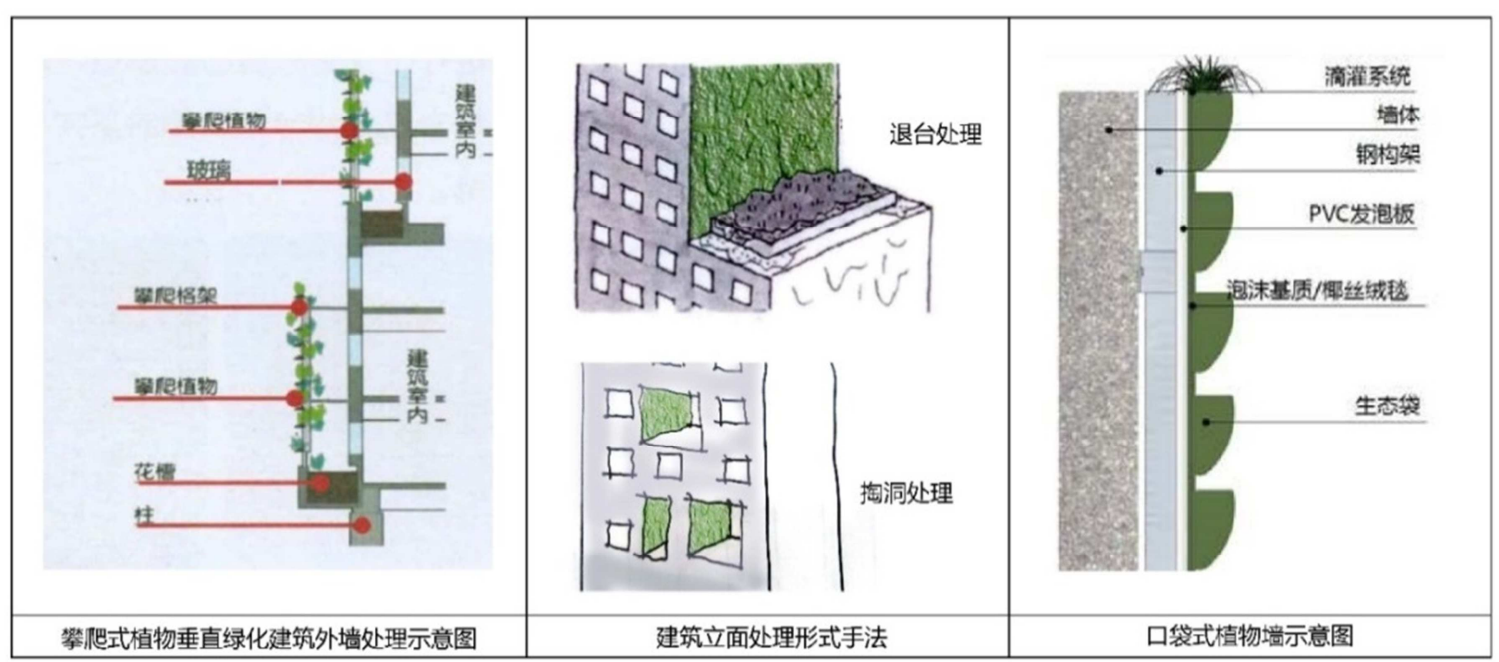

图2 建筑立面的垂直绿化处理示意图（图片来源：作者整理）。 


\section{2. 住区水循环系统机制的设立}

海绵社区的设计不单单是建筑设计一方面的事情, 而 是涉及到多学科, 多机构的复杂设计系统。从雨水循环利 用系统来说, 如图, 下雨时通过屋顶花园蓄水、存水, 通 过雨水管流入雨水箱和沉淀池, 再通过雨水花园和下沉式 绿地蓄水和渗水, 用来过滤和储存多余水资源。其他如直 接落入地面的水也会经过一系列的循环利用流程从而达 到二次利用或多次利用水的目的。

我们可从整个小区的循环系统和单个住区的用水循 环系统来看。整个循环系统主要分为水源头, 水的回收利 用, 水的路径以及水的去向四个方面。水的源头主要是市 政官网供水以及雨水的收集, 在此我们可以运用雨水花园, 雨水箱, 雨水罐等一系列收集雨水的措施。在水的回收利
用问题我们主要是解决水质问题, 可以采用沉淀池, 雨水 回用池, 雨水花园的植物截流、土壤渗滤功能来达到净化 处理作用。水的路径方面主要是依靠市政雨水管道, 植草 沟, 引水渠等汇聚, 引导来自屋顶和路面的雨水以及市政 管道的污水, 把他们输送到雨水净化装置, 主要起引导输 送作用。水的去向问题主要是解决排水的水质污染和拥堵 问题, 可以采用对水进行例如污水净化的二次处理的一系 列措施以及改善市政排水管道建设等解决办法。关于建筑 循环体制的其他补充例如水质要求可以细化到如绿水、灰 水、可饮用水、不可饮用水等, 这些不同级别的水的再次 用途可根据水质标准再进行划分, 如灰水可用来洗衣冲则 等。

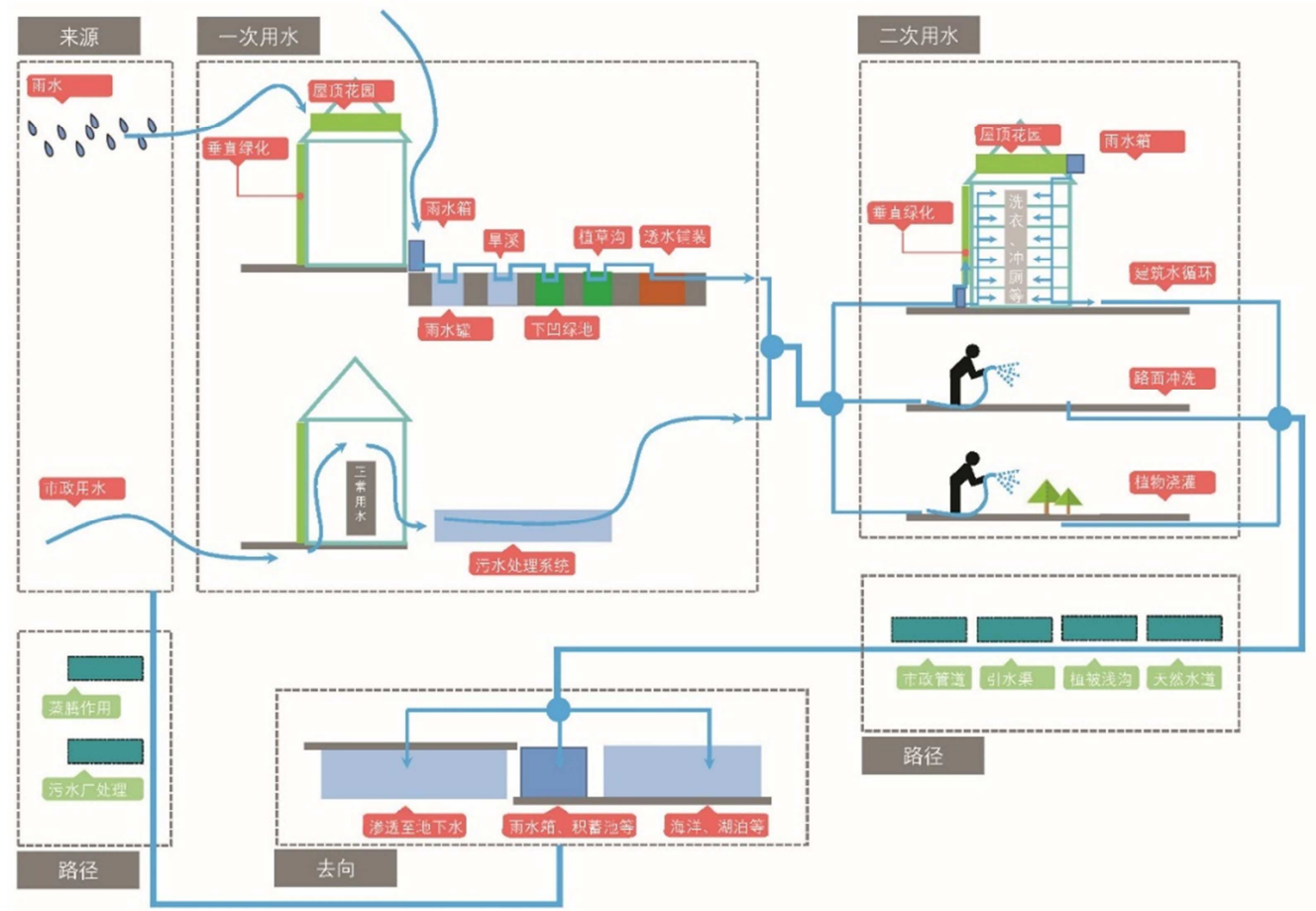

图3 海绵住区水循环示意图（图片来源：作者自绘）。

\section{3. 增强居民节水意识}

水资源不可再造, 现在雨水的主要措施是回收以及再 利用, 所以其中最重要的一点是居民思想的转变, 居民自 发的节水爱水的意识增强直接影响水资源的利用率。值得 补充一点的是现在科技的进步, 许多节水卫具都已纷纷出 现。节水卫浴及厨房节水设施的广泛采用也将有利于水资 源的高利用率。

\section{4. 海绵住区设计对我国的启示}

\section{1. 前期, 设计人员优化其设计才能, 设计单位因地制 宜, 做好设计方案}

我国海绵社区推广异常艰难的原因主要有：1设计人 员设计技术不够, 没有理解海绵社区的循环机制, 2 设计
方案生搬硬套, 不适应当地生态环境, 3各种绿色基础设 施的滥用乱搭。

对此笔者认为的解决方案有: 1设计人员扎实基础、 优化设计才能, 明晰水循环机制的前因后果, 做到设计方 案和市政管网用水相结合。2设计方案时做好前期调查, 因时制宜, 因地制宜, 根据每一个地块的独特属性定制其 专属方案，如有地形高差时根据径流方向摆放建筑物，无 地形高差时根据地块大小适当留出雨水花园广场设计空 间等。3制定出适合海绵社区的绿色基础设施标准如下凹 式绿地、旱溪、透水铺砖的尺寸, 大样图, 以及什么情况 下可采用何种具体设施, 以及如何组合各种绿色基础设施 可取得最佳效果等。

只有在前期设计方案时考虑周全, 具体情况具体分析, 才能避免后患之忧。 


\section{2. 中期, 施工方确保设计方案落实到位}

在海绵社区建设的时候, 会因为各种困难而让设计浮于 表面, 如规划设计专业人员设计方案不到位, 如设计院等一 些单位都是在设计落定的时候增加几篇海绵城市设计, 或者 在施工的时候采用的材料并不是透水性材料或者是透水性 材料的使用方法的不对。规划设计人员确保方案的落地性, 施工方需严格按照设计施工。因为海绵城市设计是多学科, 多机构共同合作进行, 建议在施工时设置专门岗位, 负责海 绵城市施工时的问题解决, 把每一小点落实到位。

\section{3. 后期, 后期监督维护, 运营管理等, 首选ppp模式}

海绵城市建设不到位, 经过研究调查可得很大一部分是 缺少激励机制和监督机制。现在比较流行的ppp模式, 如公 众、政府、金融机构三方合作，共同受益，相互监督，且推 行效果显著, 如现在有名的雄安新区等。海绵社区也可采用 新型的ppp模式，如政府、物业、居民三方合作共赢，政府 负责制定相关政策和开展相关活动, 物业公司负责落实海绵 设计相关技术，居民负责简单节水技术的使用和监督物业公 司是否落实到位以及向政府反应相关海绵设施的问题[11]。

\section{5. 结论}

根据前文总结可知, 海绵住区设计完整流程及注意事 项如下, 在海绵社区设计前期, 即方案设计时, 设计单位 需因地制宜, 因时制宜, 提前调研, 根据每个项目具体的 特征灵活变通从而设计出最适合每个地的海绵社区设计方 案。如每个项目的总图规划、建筑设计、道路停车场, 广 场花园设计等都会有不同之处, 根据地形的不同会采取不 同的布局方式，而总图规划布局和地形的差别又会采取不 同的措施如雨水花园或者下凹式绿地或者多种绿色基础设 施相结合的方式。在海绵社区设计中期, 即方案具体落地 时, 施工方需与各学科合作, 各专业人员多加强沟通合作, 需确保设计方案落实到位。在海绵社区设计后期, 即海绵 社区的管理运行与监督维护, 多采取ppp模式, 争取把政府, 民营企业, 公众都变成利益共同体, 互相监督, 共同进步 [11]。政府制定相应政策, 鼓励参与, 公众需摆正态度, 积 极参与海绵社区水循环建设, 落实节水爱水意识到点滴日 常行为中去，而民营企业也开始投入资金支持海绵社区建 设, 获得相应名利, 从而实现多方互利共赢的美好局面。 总而言之, 我国海绵城市发展正兴, 国家政策大力支 持, 海绵社区前景大好, 所以我们要积极行动, 顺势而为, 极力推行海绵社区。海绵社区的建设将是我国环境友好型 社会、资源节约型社会建设的关键一环，只有主动积极把 海绵社区的建设推行到位, 我们国家才能真正的解决城市
水问题, 从而实现人与自然和谐相处, 城市建设与社区生 态环境双方共赢的目标。

\section{致谢}

本文为国家自然科学基金资助项目 (中国)(51508422) 和武汉大学通识课项目 (中国) (413200041) 的阶段性 成果之一。

\section{参考文献}

[1] 海绵城市建设技术指南.[L].2014-10-22。

[2] 海绵城市[EB/OL].百度百科.https://baike.baidu.com/item/海 绵城市/16012711。

[3] 海绵城市建设“从抽象到具体”节能环保商机在哪? [EB/OL].环保网.

https://ecep.ofweek.com/2017-06/ART-93000-8120-3014025 9.html,(2017-06-05)[2019-11-14]

[4] 会“喝水”的城市: 海绵社区提供更舒适居住体验 $[\mathrm{EB} / \mathrm{OL}]$. 青岛早报.

http://news.qingdaonews.com/wap/2018-01/08/content_20075 059.htm, (2019-01-08)[2019-11-14]

[5] 俞孔坚, 李迪华, 袁弘, 傅微, 乔青, 王思思““海绵城市” 理论与实践 [J].城市规划, 2015,39(6):26-36。

[6] 仇保兴.海绵城市(LID)的内涵、途径与展望[J].给水排水, 2015, 41(3):1-7。

[7] 海绵型社区将成未来住区发展新趋势[EB/OL].中国风景园 林网 . http://www.chla.com.cn/htm/2015/0730/236747.html, (2017-05-30)[2019-11-14]

[8] 郑文雅.高密度住区水敏性设计策略研究[D].南京工业大 学,2016(06)。

[9] 孙菁, 市维锋. 以住区为基础的海绵城市集成技术方案探讨 [J].建筑节能, 2016。

[10] 孙芳.基于海绵城市的城市道路系统化设计研究 [D].西安 建筑科技大学, 2016。

[11] Inside china's leading 'sponge city': Wuhan's war with water [EB/OL].

Theguardian. https://www.theguardian.com/cities/2019/jan/23/inside-chinas -leading-sponge-city-wuhans-war-with-water,(2019-01-23)[20 19-11-14]. 